\title{
Defining Computational Thinking for a District: Inclusive Computing Pathways in Indian Prairie School District
}

\section{Indian Prairie School District (IPSD) 204}

\begin{tabular}{l} 
Urbanity \\
\hline Suburban \\
\hline
\end{tabular}

Number of schools
$\begin{aligned} & 31 \text { Schools } \\ & 21 \text { elementary, } 7 \text { middle } \\ & \text { school, } 3 \text { high schools }\end{aligned}$

Student enrollment

28,000
Student demographics

- $12 \%$ Latinx

- $9 \%$ Black

- $17 \%$ low-income

\section{Equity Goal}

Increase computing opportunities in a cluster of five Title I elementary schools in the district

Indian Prairie School District (IPSD) is a suburban school district serving 28,000 students in the Naperville, Aurora, Bolingbrook, and Plainfield communities outside of Chicago, Illinois. IPSD applied to participate in the National Science Foundation-funded Developing Inclusive K-12 Computing Pathways for the Leaque of Innovative Schools (Inclusive CT Pathways) project to focus on developing a K-12 pathway, aligning the computing courses available within the district. Specifically, IPSD set an equity goal of increasing computing opportunities in a cluster of five Title I elementary schools within the district. More broadly, they aimed to ensure that computing was not only occurring in specific schools or parts of the district, but rather reaches all students in the district.

\section{November 2018}

Notice the importance of inclusive CT work and inequity in district

$$
\begin{aligned}
& \text { Review CT-related } \\
& \text { groundwork }
\end{aligned}
$$

Identify leadership team

Develop shared understanding of CT
IPSD focused on providing access to computing for all students in the district, not just those who are in elective courses and after-school programs or have access through their families. They were motivated by the desire to provide students with the skills they need for future careers, building into IPSD's wider "Portrait of a Graduate" initiative.

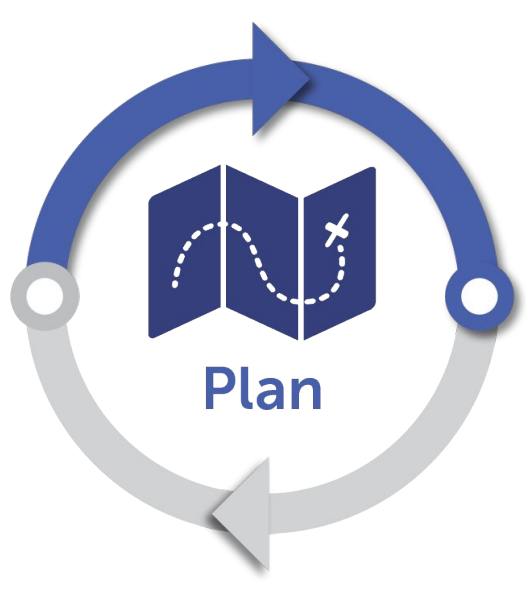

Prior to participating in the Inclusive CT Pathways project, IPSD had invested in makerspaces within each school building to provide coding opportunities and build students' problem solving, critical thinking, and reflection skills. IPSD also offered a variety of courses focused on technology broadly and computing more specifically in middle school and high school. IPSD's leadership team was their District Curriculum and Instruction Team. 
Winter 2018-2019

\section{Identify competencies}

\section{Customize competency}

map template

\section{Map to CS standards}

Vertically and horizontally align competencies

April 2019

Gather feedback and make adjustments
Since Illinois did not have computer science (CS) or computational thinking (CT) standards at the outset of the project, the IPSD team prioritized defining $\mathrm{CT}$ for their teachers and students. IPSD examined existing definitions to familiarize themselves with $\mathrm{CT}$ and determine which computing competencies to include.

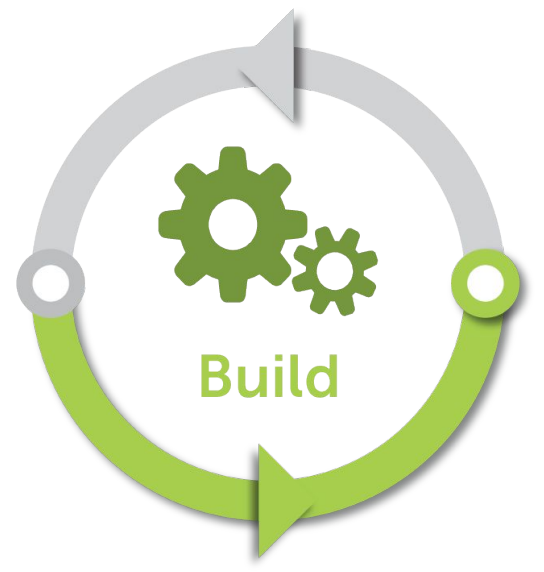

The team ultimately identified six competencies that were relevant and aligned to what was happening in IPSD:

Decomposition, Pattern Recognition, Abstraction, Algorithms, Working with Data, and Creating Computational Artifacts. The curriculum team then aligned these competencies to the K-12 CS Framework and developed their competency map. An initial draft of this map was presented to a group of K-12 teachers for feedback and reactions. The focus group provided positive reactions to the map and also offered concrete action items for its continued development.

During the 2019-2020 school year, the competency map was piloted in schools including a subset of the Title I schools highlighted in the district equity goal. The piloting included not only providing the map to teachers, but also professional development at the school level and through after-school and summer sessions.

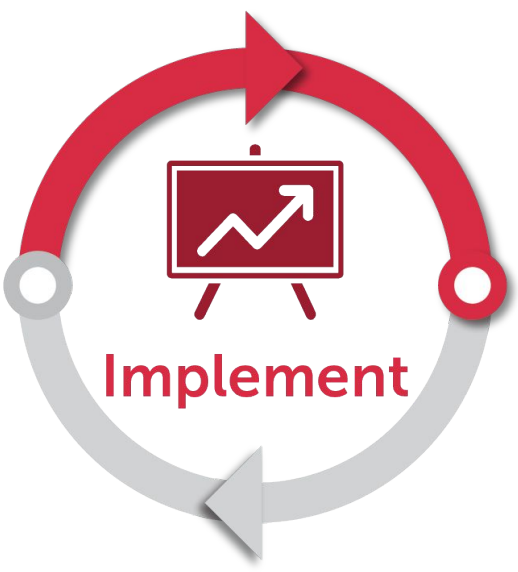

To further expand the competency map and operationalize it for teachers, particularly focusing on integration at the elementary level, a team of six teachers worked during the 2020-2021 school year to expand the map by adding classroom-relevant examples of CT-integrated lessons aligned to the IPSD standards and curricula. The team, in collaboration with district leaders, also worked on a one page summary of the map with ideas for integration activities through practical applications of the competencies and example routines, such as mind mapping. 


\section{Reflection}

\section{What are some of the key takeaways for the district?}

- Definition of CT matters and the idea of this concept can be overwhelming for teachers. IPSD was glad to have taken the time to define CT from the beginning and focus on their competencies and integration throughout the process.

- Understand what $\mathrm{CT}$ is and apply that knowledge to creating a scope and sequence for $\mathrm{CT}$.

- Leverage the competencies to enhance disciplinary learning rather than identifying $\mathrm{CT}$ only in what is already being done.

- Provide time for teachers to learn and reflect before writing and implementing lessons.

- IPSD started with the District Curriculum and Instruction team as the leaders of this initiative. This team took considerable time to learn on their own in order to become knowledgeable before expanding to teachers and building leaders. Upon reflection, including the building leaders and teachers in the learning from the beginning would have considerably helped to push the pathway forward. The district would also have brought a wider range of stakeholder experts to the table in year one, such as business leaders, to be part of the definition and planning stage.

\section{Opportunities}

Following their three years of work developing an Inclusive CT Pathway, ICCSD will next focus on:

- Creating teacher-friendly and usable guides to the IPSD Inclusive CT Pathway and a 1-page overview document.

- Expanding examples and strategies for teachers to integrate $\mathrm{CT}$, particularly in the elementary grades.

- Expanding Inclusive CT Pathway implementation to new teachers and schools across the district.

- Leveraging building experts to share ideas and best practices.

\section{District Leads:}

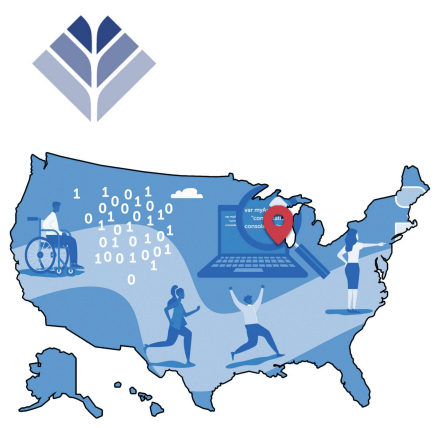

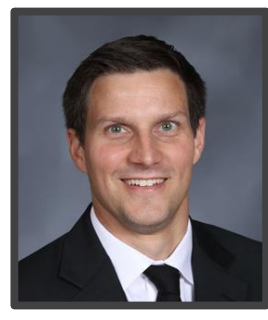

Brian Giovanini - Director of Innovation

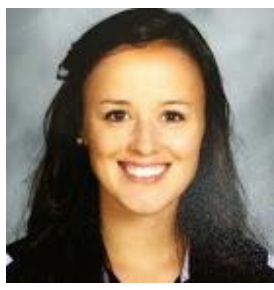

Molly Larson- Instructional

Technology Specialist

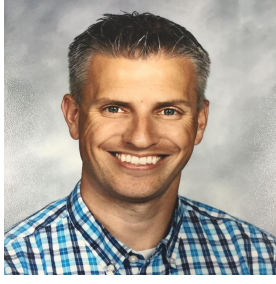

Andrew Fekete Instructional Technology Specialist

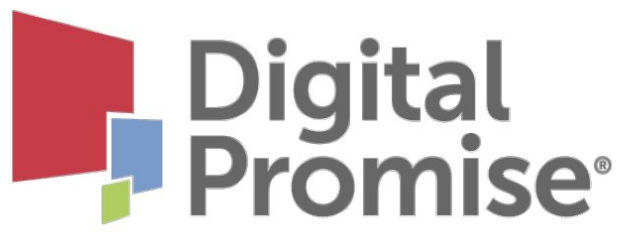

Is your district interested
Computing Pathway?

Visit the toolkit at: $\underline{\text { https://bit.ly/ }}$

CTPathwaysToolkit

Email Quinn Burke at: gburke@digitalpromise.org

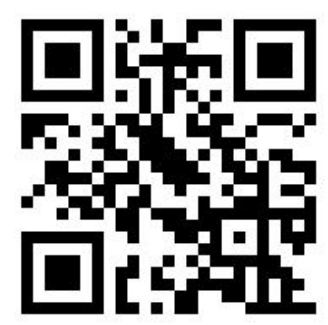

Suggested Citation:

Digital Promise. (2021). Defining computational thinking for a district: Inclusive computing pathways in Indian Prairie School District. Digital Promise. https://doi.org/10.51388/20.500.12265/131 